\title{
Hand Skin Problems: Prevalence and Risk Factors Among Nurses Working at Surgical Departments in Ministry of Health Hospitals
}

\author{
Hebatullah Abd Elrahem Fargly ${ }^{1}$, Magda Ahmed Mohammed ${ }^{2}$, Rasha Ali Ahmed ${ }^{3}$. \\ 1. B.Sc. Nursing, Al-Eman General Hospital, Assiut, Egypt. \\ 2. Professor of Medical-Surgical Nursing, Faculty of Nursing, Assiut University, Assiut, Egypt. \\ 3. Lecturer of Medical-Surgical Nursing, Faculty of Nursing, Assiut University, Assiut, Egypt.
}

\begin{abstract}
Background: Hand skin problems are widespread problems among health care members especially nurses.Aims: to determine the prevalence and risk factors of hand skin problems among nurses who are working at surgical departments in Ministry of Health Hospitals. Design: Descriptive cross-sectional study. Setting: This study was carried out at three ministry health hospitals in Assiut government: Al-Eman, Al-Shamlaa and Ophthalmology Hospitals. Sample: A purposive sample of 200 nurses working in surgical and operating room departments at Assiut ministry of health hospitals. Tool: A structured self-administrator's questionnaire, included demographic characteristic of nurses, history about hand skin problems and risk factors for hand skin problems. Results: More than one third of nurses working from 40-45 hours weekly. More than one quarter of nurses were having hand skin problems and $11.5 \%$ were complaining from hand skin problems less than one year ago. Majority of nurses had a satisfactory level of knowledge about risk factors of hand skin problems. Repeated hand washing is most common risk factors of hand skin problem. Conclusion and Recommendations: About aquarter of nurses have hand skin problems and some of them complained from hand skin problems less than one year ago. Efforts to improve skin condition must focus on improving products and identifying any interactive effects between hand care products and glove materials and brands.
\end{abstract}

\section{Keywords: Hand Skin Problems, Nurses, Prevalence \& Risk Factors.}

\section{Introduction}

Skin disorders are one of the most frequent occupation-related diseases. Occupational skin diseases are the second most common occupational diseases reported following musculoskeletal complaints (Ngajilo, 2014).

Occupational skin disease, especially hand eczema is the most common work-related disease in industrialized countries and characterized by symptoms of itching, burning, stinging or prickling and signs of dryness, erythema, fissuring, weeping, scaling, crusting, papules, vesicles, erosions and lichenification (Anandh et al., 2015, Isara \& Ofili, 2012 \& Luk et al., 2011).

Among healthcare workers, nurses are the group who at highest risk of hand eczema, the prevalence of hand eczema among nurses is reported to range from $18 \%$ to $57 \%$, depending on the nature of the work they perform and the department of employment (Ngajilo, 2014).The reported rate of allergic contact dermatitis among health-care workers ranges between 16.5 to $74 \%$ (Johansen et al., 2010 \& Skudlik et al., 2009).

Hospital work requiring regular hand washing and disinfection and it has been reported to be associated with hand eczema. A study to determine risk factors for hand eczema among nurses reported that working in a special care unit and nursing for more than 10 years were associated with hand eczema (Ni et al., 2011 \& Kim, 2010).

Risk factors of hand skin problem (eczema) can be classified as irritant, allergic, and endogenous factors such as atopic dermatitis. Exposure to skin irritants, such as water and detergents, is a major etiologic factor for developing occupational hand eczema in people who perform wet work (Lan et al., 2011).

Wet work is defined as a job requiring at least 2 hours of water exposure daily, including hair dressers, cleaners and health-care workers. Frequent and prolonged exposure to wet work may damage the protective skin barrier and increase the risk of allergic contact dermatitis ( Antunes et al., 2011).

Several previous studies have shown that occupational hand eczema affects the nurses' quality of life, with more than $20 \%$ of the affected individuals having to leave their jobs either temporarily or permanently. Therefore, a comprehensive understanding is required to prevent and reduce the prevalence of occupational hand eczema (Ni, et al., 2011).

Occupational health professionals often have to advise nurses with active hand skin problems (hand eczema ) to refrain from work until the lesions are healed, as it is difficult for them to avoid frequent hand-washing unless they are reassigned to a nonclinical area (World Health Organization, 2009). 
There are various measure help to prevent hand skin problems in nurses and reduce the problems that it causes. Occupational Health Research Foundation recommended that the regular application of emollients helps to prevent the development of occupational dermatitis, the use of antibacterial hand rub with the addition of moisturizers for hand hygiene reduces the drying and cracking of the skin that commonly results from repeated hand cleansing with soap and water (Grosse et al., 2011 \& Nicholson et al., 2010). In addition, antibacterial hand rubs are associated with increased hand hygiene compliance, reduced rates of nosocomial infection and used proper drying of the hands after washing are pivotal to good hand hygiene and care, particularly as wet skin is more likely to facilitate the transmission of bacteria than dry skin (Matterne et al., 2011 \& Dyson et al., 2011).

\section{Significance of the study}

Through a period of several years working at Ministry Health Hospitals, candidate observed that more nurses at surgical departments and special care units as operating rooms have hand skin problems. Hand problems may result in significant ongoing trouble and excess sick leave among nursing staff and not only affects quality of life but also lead to loss of employment, loss or change of job or early retirement. Also, affected individuals may experience negative psychological consequences such as sleep disturbance and interference with leisure activities. So, this study will be the first study about hand skin problems at Ministry of Health Hospitals in Assiut Governorate which helps to determine the prevalence and risk factors of hand skin problems among nurses.

\section{Aim of the study}

The present study aimed to: Determine the prevalence and risk factors of hand skin problems among nurses who working at surgical departments in Ministry of health Hospitals in Assiut Governorate.

\section{Research Question:}

What is the prevalence and risk factors of hand skin problems among nurses working at surgical departments in Ministry of health hospitals?

\section{Subjects \& Methods \\ Research design}

A descriptive cross-sectional study was conducted from June to September, 2017.

\section{Setting}

The study was conducted in surgical and operating room departments, where alcohol betadine and other disinfectant agent used mostly, at three ministries of health hospitals in Assiut Governorate, included: Al-
Eman Hospital, Al-Shamlaa Hospital (General Assiut Hospital) and Hospital of Ophthalmology.

Subjects

A sample of 200 nurses working in surgical and operating room departments. 100 nurses from AlEman Hospital, 65from Al-Shamlaa Hospital (General Assiut Hospital) and 35 from Ophthalmology Hospital).Nurses from both sexes who were willing to participate in this study.

\section{Tool of data collection:}

Tool: A structured self-administrator's questionnaire: It was developed by the researcher in Arabic language to collect information based on the relevant literatures and consulting expertise in this area to determine nurses' knowledge about hand skin problems. This tool included two parts:-

Part I: Demographic characteristic of the nurses included: Age, sex, department, marital status, residence, level of education, years of experience, work hours per week and training session about prevention of hand skin problems. Nurses and their family history of hand skin problems.

Part II: Risk factors for hand skin problems Sixteen questions about risk factors : Repeat hand washing ( how many times wash hand per day), use gloves (type of glove), have skin allergy, family history of respiratory system disorders, asthma, psychological stress, too much use of betadine and alcohol in hand washing, chemical substance, some types of soap and detergents lead to hand-skin problems, many use of soap, do not use moisturizers immediately after washing to dry the hands, changes in weather, especially cold and dry weather, antibiotic ointments containing certain compounds such as neomycin may cause problems, diseases of the immune system, hand washing with hot water in the winter, do not dry hands after washing and lack of hospital policy and job security.

Scores assigned to each item are between 0 and 1 point as follows: $(\mathbf{1}=$ yes $\boldsymbol{\&} \mathbf{0 =}$ no). According to range of total scores lie between $0-16$. Considering good knowledge as $70 \%$ of the range of total score, nurses were classified as: Satisfy about risk factors if their total score was $>10$ and were classified as unsatisfied if their total score was $<10$.

\section{Methods of data collection}

Study was conducted through:

1. A written permission to conduct the study was obtained from the research committee in Faculty of Nursing Assiut university

2. An approval was obtained from the directors of the previous settings to collect the necessary data for this study.

3. Nurses, oral permission for participation in study after explaining the aim of the study and confidentiality of obtained data was assured. 
4. At initial interview the researcher introduce herself to initiate communication, explain the nature and purpose of the study.

5. Tools development after reviewing current and international literature in the various aspects of the problems using textbooks, articles, and Journals in order to develop the study tools for data collection.

6. The tools were tested for content validity by 5 experts of academic medical and surgical nursing staff from the faculty of nursing at Assiut University. Modifications were done accordingly, and then the tools were designed in its final format and tested for reliability by using internal consistency for the tools measured using Cronbach test, the tools proved to be reliable (0.73).

Pilot Study

A pilot study carried out in April 2017 that conducted on $10 \%$ of sample in a selected setting to evaluate the applicability and clarity of the tools, it was (20) nurses whom were added to the study later. The purpose of the pilot study was: to ascertain the relevance of the tools, to detect any problem peculiar to the statements, clarity that might interfere with the process of date collection, and to estimate the time needed to complete the interview schedule.

1. Ask nurses to fill out the questionnaire sheet to assess nurses` knowledge, nurses' took10 -20 minutes to complete it.

2. Each nurse involved in the study was assessed for his or her knowledge .The study was carried out at morning and afternoon shifts.

3. Data were collected through the period from $6 / 2017$ to $9 / 2017$.

\section{Administrative design}

An official letter was issued from the Dean of the Faculty of Nursing to the Head of Surgical Departments asking the necessary approval to conduct the present research. Explain the aim of the study to them for obtaining their cooperation.

\section{Ethical considerations}

1. Research proposal was approved by Ethical Committee in Faculty of nursing.

2. There was no risk for study subjects during application of the study.

3. The study was followed the common ethical principles in clinical research.

4. Written consent was obtained from nurses that are willing to participate in the study, after explaining the nature and purpose of the study.

5. Confidentiality and anonymity was assured.

6. Nurses had the right to refuse to participate and or withdrawal from the study without any rational at any time.

\section{Statistical analysis:}

The statistical Package for (SPSS) version (23) was used to analyze data. Descriptive statistics was used for the quantitative data in knowledge and awareness questionnaire and the demographic data. Descriptive statistics included: Frequencies, percentages and cross tabulation. The level of significance for this study was set at $(p \leq 0.05)$ to detect any indication of differences found in the data available. 
Results

Table (1): Frequency distribution of demographic characteristics of the nurses participants $(\mathrm{N} .=200)$

\begin{tabular}{|c|c|c|}
\hline Variables & N. & $\%$ \\
\hline \multicolumn{3}{|l|}{ Age (years) } \\
\hline $20>30 \mathrm{yrs}$ & 67 & 33.5 \\
\hline $30>40 \mathrm{yrs}$ & 96 & 48.0 \\
\hline $40-50 \mathrm{yrs}$ & 30 & 15.0 \\
\hline More than $50 \mathrm{yrs}$ & 7 & 3.5 \\
\hline \multicolumn{3}{|l|}{ Sex } \\
\hline Male & 26 & 13.0 \\
\hline Female & 174 & 87.0 \\
\hline \multicolumn{3}{|l|}{ Marital status } \\
\hline Single & 25 & 12.5 \\
\hline Married & 168 & 84.0 \\
\hline Divorced & 6 & 3.0 \\
\hline Widow & 1 & 0.5 \\
\hline \multicolumn{3}{|l|}{ Educational level } \\
\hline Nursing bachelors & 21 & 10.5 \\
\hline Nursing institute & 110 & 55.0 \\
\hline Nursing diploma & 69 & 34.5 \\
\hline \multicolumn{3}{|l|}{ Work experience (in years) } \\
\hline$>5 \mathrm{yrs}$ & 35 & 17.5 \\
\hline $5-10 \mathrm{yrs}$ & 46 & 23.0 \\
\hline$<10 \mathrm{yrs}$ & 119 & 59.5 \\
\hline \multicolumn{3}{|l|}{ Work hours per week } \\
\hline $40>46 \mathrm{hrs}$ & 82 & 41.0 \\
\hline $46>50 \mathrm{hrs}$ & 91 & 45.5 \\
\hline More than $50 \mathrm{hrs}$ & 27 & 13.5 \\
\hline
\end{tabular}

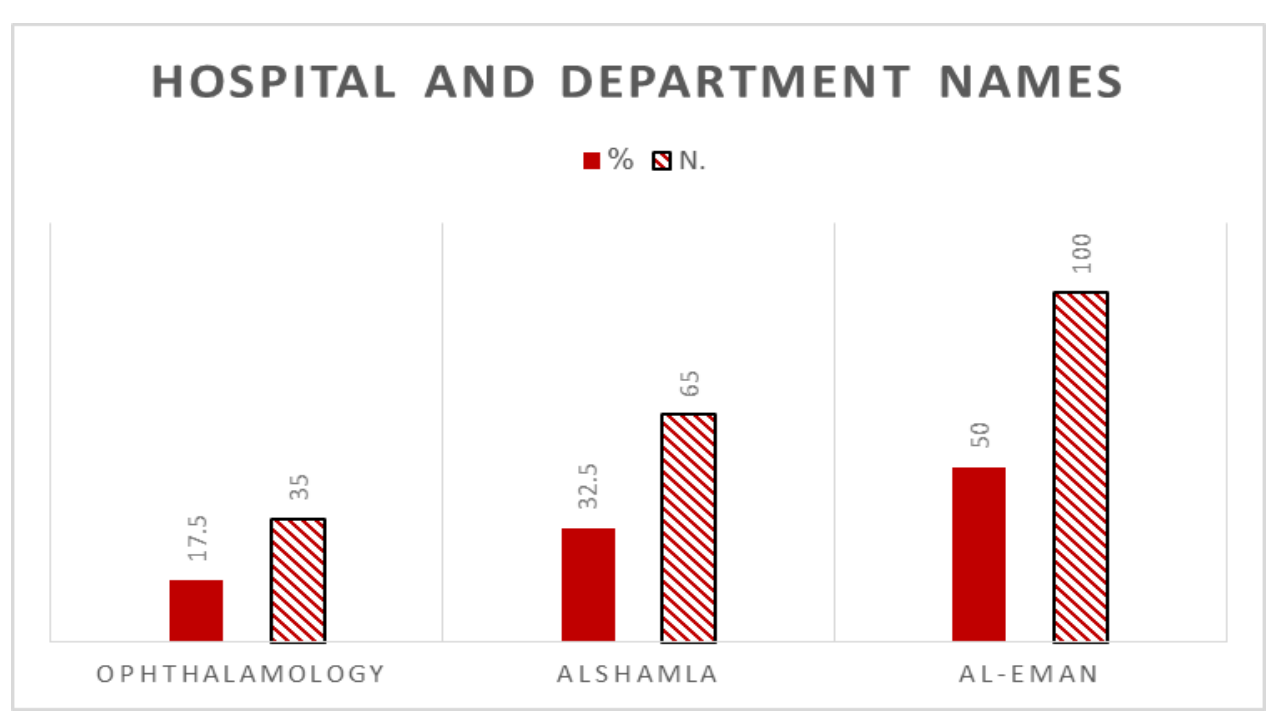

Figure (1): Frequency distribution of nurses in the three different Ministry of health hospitals 
Table (2): Frequency distribution of nurses' history and training sessions about hand skin problems (N.=200).

\begin{tabular}{|l|c|c|c|c|c|}
\hline \multicolumn{1}{|c|}{ Variables } & \multicolumn{3}{c|}{ Yes } & \multicolumn{2}{c|}{ No } \\
\cline { 2 - 6 } & N. & \% & N. & \% \\
\hline Family history about hand skin problems & 51 & 25.5 & 149 & 74.5 \\
\hline Have skin disease or allergy & 47 & 23.5 & 153 & 76.5 \\
\hline Training session about prevention of hand skin problems & 14 & 7.0 & 186 & 93.0 \\
\hline Time of attendance & \multicolumn{5}{|l}{} \\
\hline Less than one year & 5 & $2.5 \%$ & & \\
\hline one - 2 years & 6 & $3.0 \%$ & & \\
\hline 3-4 years & 3 & $1.5 \%$ & & \\
\hline Duration of training & & 11 & $5.5 \%$ & & \\
\hline One day & 3 & $1.5 \%$ & & \\
\hline Three days &
\end{tabular}

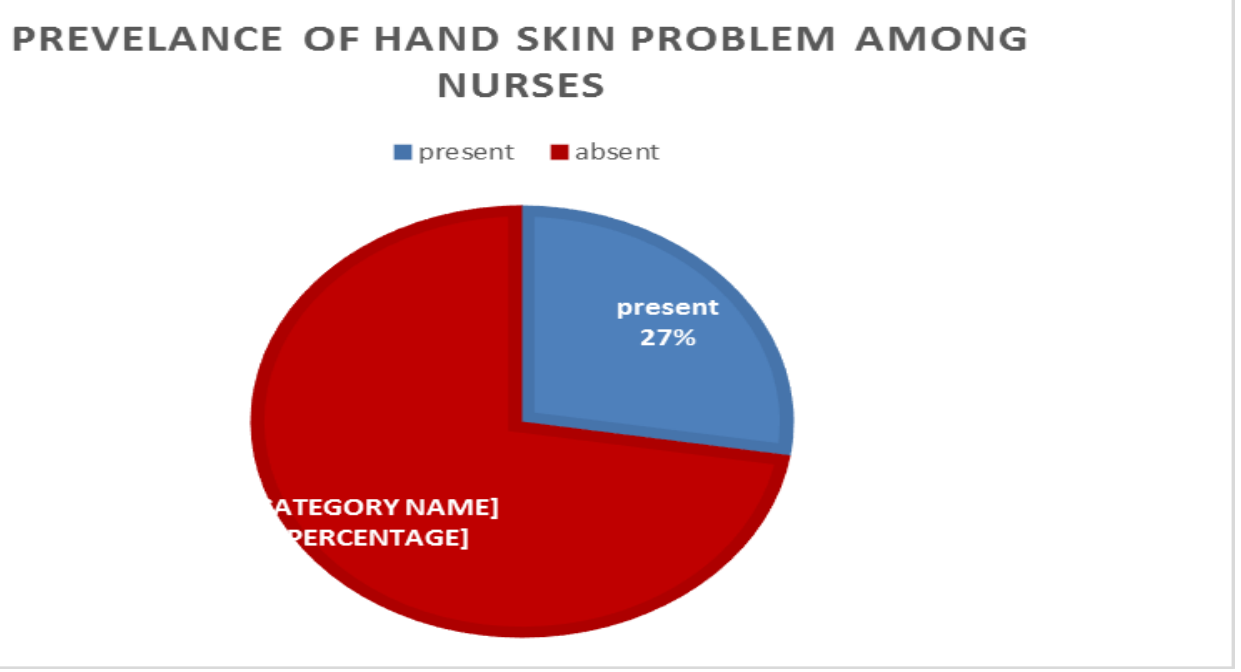

Figure (2): Prevalence of hand skin problems among nurses $\left(\mathbf{N}_{.}=200\right)$

Table (3): Comparison between risk factors for three different ministry health hospitals regarding hand skin problems $(\mathbf{n}=\mathbf{2 0 0})$

\begin{tabular}{|c|c|c|c|c|c|c|c|}
\hline \multirow{2}{*}{ Risk factors } & \multicolumn{2}{|c|}{ Al-Eman } & \multicolumn{2}{|c|}{ Al-Shamlaa } & \multicolumn{2}{|c|}{ Ophthalmology } & \multirow{2}{*}{ p.value } \\
\hline & N. & $\%$ & N. & $\%$ & N. & $\%$ & \\
\hline \multicolumn{8}{|l|}{ Repeat washing hands } \\
\hline Yes & 100 & 100. & 54 & 83.1 & 34 & 97.1 & \multirow{2}{*}{$0.001 * *$} \\
\hline No & 0 & 0.0 & 11 & 16.9 & 1 & 2.9 & \\
\hline \multicolumn{8}{|l|}{ if yes } \\
\hline $1-5$ times $\backslash$ days & 1 & 1.0 & 2 & 3.1 & 1 & 2.9 & \multirow{3}{*}{$0.001 * *$} \\
\hline 5-10 times \days & 44 & 44.0 & 17 & 26.2 & 17 & 48.6 & \\
\hline more than 10 timesldays & 55 & 55.0 & 36 & 55.4 & 16 & 45.7 & \\
\hline \multicolumn{8}{|l|}{ Use of gloves } \\
\hline Yes & 93 & 93.0 & 59 & 90.8 & 35 & 100 & \multirow{2}{*}{$0.19 \mathrm{~ns}$} \\
\hline No & 7 & 7.0 & 6 & 9.2 & 0 & 0.0 & \\
\hline \multicolumn{8}{|l|}{ Types of gloves } \\
\hline Rubber & 11 & 11.0 & 0 & 0.0 & 6 & 17.1 & \multirow{3}{*}{$\mathbf{0 . 0 0 2} * *$} \\
\hline Latex & 70 & 70.0 & 56 & 86.2 & 21 & 60. & \\
\hline Rubber and Latex & 12 & 12.0 & 3 & 4.6 & 8 & 22.9 & \\
\hline
\end{tabular}




\begin{tabular}{|c|c|c|c|c|c|c|c|}
\hline \multirow{2}{*}{ Risk factors } & \multicolumn{2}{|c|}{ Al-Eman } & \multicolumn{2}{|c|}{ Al-Shamlaa } & \multicolumn{2}{|c|}{ Ophthalmology } & \multirow{2}{*}{ p.value } \\
\hline & $\mathrm{N}$. & $\%$ & N. & $\%$ & $\mathrm{~N}$. & $\%$ & \\
\hline \multicolumn{8}{|l|}{ Chemical substance } \\
\hline Yes & 83 & 83.0 & 58 & 89.2 & 32 & 91.4 & \multirow{2}{*}{$0.33 \mathrm{~ns}$} \\
\hline No & 17 & 17.0 & 7 & 10.8 & 3 & 8.6 & \\
\hline Soap liquid & 1 & 1.0 & 10 & 15.4 & 6 & 17.1 & \multirow{7}{*}{$0.002 * *$} \\
\hline Betadine & 2 & 2.0 & 1 & 1.5 & 3 & 8.6 & \\
\hline Alcohol & 7 & 7.0 & 5 & 7.7 & 2 & 5.7 & \\
\hline Cholor & 10 & 10.0 & 11 & 16.9 & 4 & 11.4 & \\
\hline Soap liquid and cholor & 11 & 11.0 & 13 & 20.0 & 5 & 14.3 & \\
\hline Alcohol and betadine & 9 & 9.0 & 8 & 12.3 & 4 & 11.4 & \\
\hline $\begin{array}{l}\text { Alcohol, betadine, Soap liquid } \\
\text { and cholor }\end{array}$ & 43 & 43.0 & 10 & 15.4 & 8 & 22.9 & \\
\hline
\end{tabular}

Chi-Square Test

$*=$ Significant difference $* p \leq 0.05 \quad * *=$ highly significance $* p \leq 0.01 \quad$ Ns $=$ Non significant difference P $\geq 0.05$

Table (4): Comparison of total knowledge regarding risk factors of hand skin problems among nurses in three different ministry health hospitals ( $N=200)$.

\begin{tabular}{|c|c|c|c|c|c|c|c|}
\hline \multirow{2}{*}{ Items } & \multicolumn{2}{|c|}{ Al-Eman } & \multicolumn{2}{|c|}{ Al-Shamlaa } & \multicolumn{2}{|c|}{ Ophthmology } & \multirow{2}{*}{$\begin{array}{c}\text { p. } \\
\text { value }\end{array}$} \\
\hline & $\mathrm{N}$. & $\%$ & N. & $\%$ & N. & $\%$ & \\
\hline \multicolumn{7}{|c|}{ Total knowledge score $(0-16)$} & \\
\hline Satisfy & 93 & 93.0 & 48 & 73.8 & 22 & 62.9 & \multirow[t]{2}{*}{$0.001 * *$} \\
\hline Unsatisfied & 7 & 7.0 & 17 & 26.2 & 13 & 37.1 & \\
\hline
\end{tabular}

Table (5): Comparison of total knowledge regarding risk factors of hand skin problems among nurses in operating room and surgical department regarding the three different ministry health hospitals (N.=200)

\begin{tabular}{|c|c|c|c|c|c|}
\hline \multirow[t]{2}{*}{ Items } & \multicolumn{2}{|c|}{$\begin{array}{c}\text { Operating } \\
\text { room }\end{array}$} & \multicolumn{2}{|c|}{ Surgical department } & \multirow{3}{*}{ p. value } \\
\hline & $\mathrm{N}$. & $\%$ & N. & $\%$ & \\
\hline \multicolumn{5}{|c|}{ Total knowledge } & \\
\hline Satisfy & 30 & 32.3 & 25 & 23.4 & \multirow{2}{*}{$0.001 * *$} \\
\hline Unsatisfied & 63 & 67.7 & 82 & 76.6 & \\
\hline
\end{tabular}

Chi-Square Tests $\quad *=$ Significant difference $*^{*} \leq 0.05 \quad * *=$ highly significance $* p \leq 0.01$

Table (6): Comparison between prevalence of hand skin problems among nurses in different ministry health hospitals $(\mathbf{N}=\mathbf{2 0 0})$.

\begin{tabular}{|c|c|c|c|c|c|c|c|c|}
\hline \multirow{2}{*}{ Items } & \multicolumn{2}{|c|}{ Al-Eman } & \multicolumn{2}{|c|}{ Al-Shamlaa } & \multicolumn{2}{|c|}{ Ophthmology } & Total & \multirow{3}{*}{$\begin{array}{c}\text { P. } \\
\text { value }\end{array}$} \\
\hline & N. & $\%$ & N. & $\%$ & N. & $\%$ & \multirow{2}{*}{200} & \\
\hline \multicolumn{7}{|c|}{ Hand skin problems } & & \\
\hline Yes & 32 & 32.0 & 13 & 20 & 10 & 28.6 & 55 & \multirow{2}{*}{0.23} \\
\hline No & 68 & 68.0 & 52 & 80.0 & 25 & 71.4 & 145 & \\
\hline
\end{tabular}


Table (7): Comparison between risk factors of hand skin problems among nurses suffering form hand skin problems $(\mathbf{N}=55)$.

\begin{tabular}{|c|c|c|c|c|c|}
\hline \multirow{3}{*}{ Risk factors } & \multicolumn{4}{|c|}{ Hand skin problems } & \multirow{3}{*}{ p. value } \\
\hline & \multicolumn{2}{|c|}{ Yes } & \multicolumn{2}{|c|}{ No } & \\
\hline & N. & $\%$ & N. & $\%$ & \\
\hline Repeat hand washing. & 50 & 90.9 & 5 & 9.1 & $0.03 *$ \\
\hline $1-5$ times & 1 & 2.8 & 0 & 0 & \multirow[t]{3}{*}{$0.44 \mathrm{~ns}$} \\
\hline 6-10 times & 18 & 32.7 & 0 & 0 & \\
\hline More than 10 times & 31 & 56.4 & 0 & 0 & \\
\hline Use of gloves & 52 & 94.5 & 3 & 5.5 & $0.04 *$ \\
\hline Rubber & 7 & 12.7 & 0 & 0 & \multirow{3}{*}{$0.04 *$} \\
\hline Latex & 34 & 61.8 & 0 & 0 & \\
\hline Rubber and latex & 11 & 20.0 & 0 & 0 & \\
\hline Chemical substance & 45 & 81.8 & 10 & 18.2 & $0.016 *$ \\
\hline Dermatology or Skin Allergy & 31 & 56.4 & 24 & 43.6 & $0.00 *$ \\
\hline $\begin{array}{l}\text { Family history of respiratory disease and } \\
\text { Asthma }\end{array}$ & 16 & 29.1 & 39 & 70.9 & $0.003 *$ \\
\hline Stress and psychological stress & 24 & 43.6 & 31 & 56.4 & $0.003 *$ \\
\hline Many use soap & 40 & 72.7 & 15 & 27.3 & $0.03 *$ \\
\hline $\begin{array}{l}\text { Some types of soap and detergents lead to hand- } \\
\text { dermatitis }\end{array}$ & 51 & 92.7 & 4 & 7.3 & $0.05 *$ \\
\hline $\begin{array}{l}\text { Do not use moisturizers immediately after } \\
\text { washing to dry the hands }\end{array}$ & 44 & 80.0 & 11 & 20.0 & $0.02 *$ \\
\hline $\begin{array}{l}\text { Changes in weather, especially cold and dry } \\
\text { weather }\end{array}$ & 45 & 81.8 & 10 & 18.2 & $0.02 *$ \\
\hline $\begin{array}{l}\text { Antibiotic ointments containing certain } \\
\text { compounds such as Neomycin may cause } \\
\text { dermatitis }\end{array}$ & 45 & 81.8 & 10 & 18.2 & $0.02 *$ \\
\hline Diseases of the immune system & 36 & 65.5 & 19 & 34.5 & $0.001 * *$ \\
\hline $\begin{array}{l}\text { Hand washing with hot water in the winter leads to } \\
\text { hand-dermatitis }\end{array}$ & 50 & 90.9 & 5 & 9.1 & $0.03 *$ \\
\hline $\begin{array}{l}\text { Do not dry your hands after washing them, leading } \\
\text { to inflammation of the skin of the hands }\end{array}$ & 50 & 90.9 & 5 & 9.1 & $0.03 *$ \\
\hline $\begin{array}{l}\text { Too much use of beta dine and alcohol in hand } \\
\text { washing }\end{array}$ & 44 & 80.0 & 11 & 20.0 & $0.02 *$ \\
\hline Lack of hospital policy and job security & 33 & 60.0 & 22 & 40.0 & $0.01 *$ \\
\hline
\end{tabular}

Chi-Square Tests

$*=$ Significant difference $*_{p} \geq 0.05 * *=$ highly significance $* p \leq 0.01 \quad$ Ns $=$ Non significant difference $P \geq 0.05$

Table (8): Relation between demographic data and nurses suffering from hand skin problems $(\mathrm{N}=55)$

\begin{tabular}{|c|c|c|c|c|c|}
\hline \multirow{3}{*}{ Variables } & \multicolumn{4}{|c|}{ Nurses with hand skin problems } & \multirow{3}{*}{ p. value } \\
\hline & \multicolumn{2}{|c|}{ Yes } & \multicolumn{2}{|c|}{ No } & \\
\hline & N. & $\%$ & N. & $\%$ & \\
\hline $20>30$ years & 13 & 23.6 & 54 & 37.2 & \multirow{4}{*}{$0.28 \mathrm{~ns}$} \\
\hline $30>40$ years & 30 & 54.5 & 66 & 45.5 & \\
\hline $40>50$ years & 9 & 16.4 & 21 & 14.5 & \\
\hline More than 50 years & 3 & 5.5 & 4 & 2.8 & \\
\hline \multicolumn{6}{|l|}{ Sex } \\
\hline Male & 8 & 14.5 & 18 & 12.4 & $0.42 \mathrm{~ns}$ \\
\hline
\end{tabular}




\begin{tabular}{|c|c|c|c|c|c|}
\hline \multirow{3}{*}{ Variables } & \multicolumn{4}{|c|}{ Nurses with hand skin problems } & \multirow{3}{*}{ p. value } \\
\hline & \multicolumn{2}{|c|}{ Yes } & \multicolumn{2}{|c|}{ No } & \\
\hline & 47 & 85.5 & 127 & 87.6 & \\
\hline \multicolumn{6}{|l|}{ Level of education } \\
\hline Nursing bachelors & 6 & 10.9 & 15 & 10.3 & \multirow{3}{*}{$0.99 \mathrm{~ns}$} \\
\hline Nursing institute & 30 & 54.5 & 80 & 55.2 & \\
\hline Nursing diploma & 19 & 34.5 & 50 & 34.5 & \\
\hline \multicolumn{6}{|l|}{ Work Experience } \\
\hline$>5$ years & 7 & 12.7 & 28 & 19.3 & \multirow{3}{*}{$0.32 \mathrm{~ns}$} \\
\hline $5-10$ years & 16 & 29.1 & 30 & 20.7 & \\
\hline$<10$ years & 32 & 58.2 & 87 & 60.0 & \\
\hline \multicolumn{6}{|l|}{ Work hours per week } \\
\hline $40-45 \mathrm{hrs}$ & 33 & 60.0 & 49 & 33.8 & \multirow{3}{*}{$\begin{array}{c}0.001 \\
* *\end{array}$} \\
\hline $46-50 \mathrm{hrs}$ & 17 & 30.9 & 74 & 51.0 & \\
\hline More than $50 \mathrm{hrs}$. & 5 & 9.1 & 22 & 15.2 & \\
\hline
\end{tabular}

Chi-Square Tests

$*=$ Significant difference $\quad * p \leq 0.05 \quad * *=$ highly significance $* p \leq 0.01 \quad N s=$ Non significant difference $P \geq 0.05$

Table (1): This table showed that: The majority of nurses were females $(87.0 \%)$, age range between 31 40 years old $(48 \%)$, and the majority of them were married $(84.0 \%)$. More than half of nurses were having nursing institute $(55 \%)$ and more than 10 years of experience $(59 \%)$. More than one third of nurses working from 40-45hours weekly (41\%) and 46-50 hours weekly (45.5\%).

Figure (1): Showed that more than half of nurses working in surgical department $(53 \%)$ and half of them working at $\mathrm{Al}$-Eman hospital (50\%).

Table (2): showed that (25.5\%) of nurses have family history about hand skin problems and (23.5\%) have skin allergy or disease. In addition, showed that $(93.0 \%)$ of nurses were not attaining any training session about prevention of hand skin problems.

Figures (2) Illustrated that $(27.5 \%)$ of nurses have hand skin problems and $(11.5 \%)$ complained from hand skin problems less than one year ago.

Table (3): This table showed that statistical significant different between three ministry health hospitals regarding risk factors except use of gloves and chemical substance p-value (0.19 and 0.33 respectively )

Table (4): This table showed that there was a statistical significance difference between three ministry health hospitals regarding total knowledge score $(\mathrm{P}=0.001)$

Table (5): This table illustrated that there was statistical significant difference between the operating and surgical departments as regarding total knowledge score $(\mathrm{P}=0.001)$.

Table (6): This table showed that there was no statistical significant different between three different ministry health hospitals regarding prevalence of hand skin problems $(\mathrm{P}$-value $=0.23)$
Table (7): This table showed that there was a statistical significant difference as regarding risk factors of hand skin problems for nurses with hand skin problems in three different ministry health hospitals

Table (8): This table showed there was no statistical significant difference as regarding age, sex, level of education and work experience with nurses having skin problems ,but, statistical significant difference as regard work hours per week among nurses having hand skin problems value (p-0.001).

\section{Discussion}

Health care institution like other high risk work settings characterized by a high level of exposure to hazardous agents, which dramatically endangers the health and life of healthcare workers (Abidoye et al., 2016).

Hand skin problem is regarded as one of the most often observed dermatological disorders among nurses (Szepietowski \& Salomon, 2005)

Occupational skin disease, especially hand eczema, is the most common work-related disease in industrialized countries (Sang et al., 2013).

This cross sectional study was carried out to determine the prevalence of skin hand problems among nurses, and risk factors associated with skin hand problems.

Based on the results of the present study, the majority of nurses were females, married, age ranged between 31-40yrs, above half of them have a nursing institute and years of experience above 10 years and more than one third of nurses were working from 40-50 hours weekly. These results agree with (Mahmood et al., 2015): Who reported that the majority of the 
healthcare workers were females (72.0\%), aged between $31-40$ years $(60.0 \%)$.

Most of nurses weren't attaining any training sessions about prevention of hand skin problems, shown in table 4. This was supported by Dyrbye \& Shanafelt, (2016) who reported that there was a lack of medical treatment and unavailability of an occupational safety and health policy in place.

While Mahmood et al.,(2015) was disagreeing with those results as reported that the majority of the healthcare workers had received formal training in hand hygiene in the last 3 years. In addition, our results reveled that, around half of the nurses didn't receive safety and health training.

Demirkesen, \& Arditi, (2015) reported that respondents did not take a training regarding safety practices. Opposite to the results of the present study (Eljedi, 2015) reported that availability of safety guidelines were presented in their facility. The most of training program for nurses in our hospitals usually away from this important issue (hand skin problems). So the safety guidelines for nurses about how to protect themselves from hand dermatitis is very important and workplace safety must be a priority for both administration and health care workers.

Regarding the prevalence of hand skin problems among nurses, the current study explored that about one third of nurses were having a history of hand skin problems, and $11.5 \%$ of them complaining from hand skin problems less than one year ago. This is considered a serous indicator. We were unable to find national statistics with which to compare our prevalence directly.

However, Kokandi, (2017) reported that the percentage of self-reported hand dermatitis was $7.73 \%$. The incidence of hand dermatitis among nurses varied in different countries in different studies. In Germany, the prevalence of hand eczema was reported to be $18 \%$ in a study on 1375 geriatric nurses from 86 nursing homes (Ibler et al., 2012). A questionnaire survey reported a 1 year prevalence of hand dermatitis of $21 \%$ among healthcare workers in three hospitals in Denmark (Luk et al., 2011).

When we return to the results of this study to found out the information of nurses about the risk factors of hand-skin diseases, the majority of nurses have knowledge about risk factors of hand skin problems with statistical significance difference between three different ministry health hospitals regarding total knowledge score. The Majority of nurses knowledge about risk factors of hand skin problems according to nurses response are: repeat washing hands, use of gloves, do not dry hands after washing them, chemical substance, some types of soap and detergents lead to hand skin problems, hand washing with hot water in the winter leads to hand skin problems and too much use of beta dine and alcohol in hand washing.

Most the three ministry health hospital nurses were exposed to strong chemical disinfecting materials. The exposure to chemical disinfecting materials depends on departments. The longest duration of contact with disinfecting materials was found for nurses of operating rooms and surgical departments. All nurses under study using chemical disinfecting materials had most frequent contact with chlorine and alcohols. Liquid soap and betadine were less often used. The type of chemicals used depended on the kind of medical procedures carried out.

The results showed the differences between departments. Alcohols, betadine, soap and cholor were predominantly used at operating rooms and surgical departments. Damage to the skin develops after the effect of irritant or toxic substances and depends on their chemical characteristics and concentration as well as on the properties of the epidermis.

Owing to the nature of their job, nurses are required to wash their hands frequently, perform wet work, wear occlusive rubber gloves for long periods, and are in a regular contact with disinfectants, detergents, and medical substances ( Lan et al., 2011 \& Luk et al., 2011) Constant exposure to these irritants may lead to cumulative damage to the skin barrier, which manifests initially as dryness, discomfort and progressively worsens to eczema. This irritant contact dermatitis can be acute (wet weepy red vesicular lesions) or chronic (thickened lichenified lesions). Importantly, disruption of the skin barrier may predispose a person to allergen sensitization and allergic contact dermatitis ( Ngajilo, 2014).

Regarding gloves used, most of nurses used latex gloves and above have of nurses wash hand more than 10 times per day in this study. This study results were on the same line with (Cao et al., 2010) who reported that most health care facilities are shifting from using natural rubber latex to synthetic rubber gloves, people require knowledge on the various rubber chemicals present in these alternate synthetic rubber gloves, to which the skin may be exposed during use. This will be helpful in managing rubber glove chemical induced allergic contact dermatitis and sensitization.

Sang et al., (2013) reported that risk factors for occupational hand dermatitis were young age, history of atopic dermatitis, washing hands more than 20 times a day and wearing gloves for more than 5 minutes a day; frequent use of hand moisturizers decreased the risk of hand eczema. Atopic dermatitis and the frequency of hand washing are known to be the relative coherent risk factors for hand eczema. In 
atopic dermatitis, alterations of skin barrier function and the immune system may contribute to occupational hand dermatitis.

Wetzky et al., (2009) reported that the glove itself did not cause the dysfunction of the skin barrier. On the other hand, (Jungbauer et al., 2004) showed that when wearing gloves after washing hands with water and soap, the residue from the soap remained on the skin, and when the hands were sealed with gloves, the irritancy of the soap was maximized, causing hand eczema.

Nurses had knowledge about hand skin problems but the preventive measures were not sufficient available. On the other hand some of them have skin dermatitis, because they do not follow the precautions necessary to prevent problems of hand skin or the reasons due to the lack of sufficient facilities and adequate safety measures to protect them from that injury. So the nurse should have knowledge on risk factors and also being able to identify early signs of dermatitis. This is similar to findings in a study that investigated risk factors suggested in this previous study included young age, history of atopic dermatitis, frequent hand washing and long duration of glove wearing (Kokandi, 2017).

The results of this study founded that, there were a statistical significant difference between the operating rooms and surgical department as regarding total nurses knowledge score, , an increase in the knowledge of nurses working in the operating room of those who were working in the surgery department, but still little numbers have a satisfactory knowledge.

Prevention of skin diseases is an important part of occupational health services management and programs especially in the health care industry. Damage to the skin barrier puts the worker at risk of infectious disease and predisposes to microorganism carriage and risk to patients. (Holt et al., 2014).

In summary, this study has shown that knowledge of healthcare related hand skin problem and risk factors is sufficient among nurses, but nurses not attaining any training session about prevention of hand skin problems leading to wrong behavior at work and insufficient use of skin protection and skin care products. Regular teaching and better information might decrease the prevalence of dermatitis in nurses.

\section{Conclusion}

Based on the results of the present study, it can be concluded that

Most of nurses had not attained any training session about prevention of hand skin problems. About quadrate of nurses have hand skin problems and some of them complained from hand skin problems less than one year ago.

\section{Recommendations}

Based on results of the present study the following can be recommended

- Use water-based moisturizers after washing hands.

- Follow hand washing guidelines to use warm water, the least harsh soap for routine hand washing and dry hands thoroughly after washing.

- Use a heavier, oil-based moisturizer under cotton gloves at home or away from work to help heal severely dry skin.

\section{For further research}

- Replication of the study on a larger probability sample in different geographical areas in Egypt to figure out the main aspects of these problems.

\section{References}

1. Abidoye A., Adebisi T., Aluko O., Ewegbemi M., \& Popoola B., (2016): Knowledge, attitudes and perceptions of occupational hazards and safety practices in Nigerian healthcare workers. BMC Research Notes, volume 9(1),P. 71.

2. Demirkesen, S., \& Arditi, D., (2015): Construction safety personnel's perceptions of safety training practices. International Journal of Project Management, 33(5), 1160-1169.

3. Anandh B., Jayachandran P., Josephin D., KalpanaB.,Senthil A., Thangavel G., \& Yamini R., (2015): Perception and prevalence of workrelated health hazards among health care workers in public health facilities in southern India. International journal of occupational and environmental health,volume 21(1),Pp. 74-81.

4. Antunes J., Silva R., Pacheco D., Travassos R., \& Filipe P., (2011): Occupational contact allergy to cephalosporins. Dermatology Online Journal;volume 17: P.13.

5. Dyson J., Lawton R., Jackson C., \& Cheater F., (2011): Does the use of a theoretical approach tell us more about hand hygiene behaviour? The barriers and levers to hand hygiene. Jaurnal InfectionPrevtion.; volume12(1):Pp:17-24.

6. Eljedi A., (2015): "Prevalence and response to Occupational Hazards among Nursing Students in Gaza Strip, Palestine: The role of Personal Protective Equipment and Safety Regulations." Public Health Research volume5(1): PP: 32-38.

7. Grosse-Schutte K., Assadian O., Hubner NO., Loffler H., \& Kramer A., (2011): Practices of skin care among nurses in medical and surgical intensive care units: results of a self-administered questionnaire.

GMS KrankenhhygInterdiszip.volume6: P1.

8. Ibler K., Jemec G., Flyvholm M., Diepgen T., Jensen A., \& Agner T., (2012): Hand eczema: prevalence and risk factors of hand eczema in a 
population of 2274 healthcare workers. Contact Dermatitis 2; volume67:PP. 200-207.

9. Isara A., \& Ofili A., (2012): Prevalence of occupational accidents/Injuries among health care workers in a federal medical Centre in southern Nigeria. West Afr J Med., volume31 (1): Pp. 4751.

10. Johansen J., Linneberg A., \& Menné T., (2010): The epidemiology of hand eczema in the general population - Prevalence and main findings. Contact Derm. volume62 (2): PP. 7587.

11. Kim G., (2010): The patch test as a useful tool for avoiding suspected allergens in patients with hand eczema. Korean J Dermatol;volume 47:Pp. 26 32.

12. Kokandi AA., (2017): Hand dermatitis among nurses at a University Hospital in Saudi Arabia. Biomedical Research , Biomed Res- India . Volume 28, Issue 152017; 28 (15): PP. 66876692

13. Lan C-CE, Tu H-P, Lee C-H, Wu C-S, Ko YC, Yu H-S. ,(2011):Hand dermatitis among university hospital nursing staff with or without atopic eczema: assessment of risk factors. Contact Dermatitis.volume;64(2):pp.73-79.

14. Luk N., Lee H., Luk C., Cheung Y., Chang M., Chao V., Ng S., \& Tang L., (2011): Hand eczema among Hong Kong nurses: a self-report questionnaire survey conducted in a regional hospital. Contact Dermatitis; volume65: pp. 329335 .

15. MahmoodS. E., Verma Rakhee \& Khan M., (2015): Hand hygiene practices among nursing students: importance of improving current training programs, International Journal of Community Medicine and Public Health, Vol 2 | Issue 4 . PP.466-471

16. Matterne U., Diepgen T., \& Weisshaar E., (2011): A longitudinal application of three health behavior models in the context of skin protection behavior in individuals with occupational skin disease. Psychol Health.vol. 26(9):Pp.1188-207.

17. Ngajilo D., (2014): Occupational contact dermatitis among nurses: a report of two cases, current allergy \& clinical immunology .volume 27 no.1,PP.42-46.

18. Ni C., Dou X., Chen J., Zhu X., \& Lin L., (2011): Contact sensitization in Chinese patients with hand eczema. Dermatitis;vol.22: Pp.211-215

19. Nicholson P., Llewellyn D., \& English J.,(2010): Evidence-based guidelines for the prevention, identification and management of occupational contact dermatitis and urticaria. Contact Dermatitis;volume63:PP.177-186.
20. Sang Lee W., Cheong S., Byun J., Choi Y., and Choi H., (2013): Occupational hand eczema among nursing staffs in Korea: Self-reported hand eczema and contact sensitization of hospital nursing staffs. J Dermatol;volume 40: PP. 182187.

21. Skudlik C., Dulon M., Wendeler D., John S., \& Nienhaus A., (2009): Hand eczema in geriatric nurses in Germany - Prevalence and risk factors. Contact Derm.; vol. 60(3):Pp. 136-43.

22.Szepietowski J., \& Salomon J., (2005):Hand dermatitis, a problem commonly affecting nurses. RoczAkad Med Bialymst, volume 1:PP.46-8.

23. Wetzky U., Bock M., Wulfhorst B., \& John S., (2009): Short- and long-term effects of single and repetitive glove occlusion on the epidermal barrier. Arch Dermatol Res; volume301: pp.595602.

24. World Health Orgnization, (2009): Guidelines on hand hygiene in health care. Available at Web site: www.who.int/patientsafety

25. Dyrbye, L., \& Shanafelt, T., (2016): A narrative review on burnout experienced by medical students and residents. Medical education, 50(1), 132-149.

26. Holt, S., Cai, M., Ryan, A., \& McMahon, L., (2014): Providing a Peritoneal Dialysis Service. In Practical Nephrology(pp. 705-716). Springer, London.

27. Jungbauer F., Van Der Harst J., Groothoff J., \& Coenraads P., (2004): Skin protection in nursing work: promoting the use of gloves and hand alcohol. Contact Dermatitis; volume51: P.135-140.

28. Cao L., Taylor J., Sood A., Murray D., \& Siegel P., (2010): Allergic contact dermatitis to synthetic rubber gloves: changing trends in patch test reactions to accelerators. Arch Dermatol; volume 146(9):PP.1001-7. 